\title{
Laparoscopic pancreatic neck transection and double pancreatico-jejunostomy, an alternative surgical approach to chronic pancreatitis
}

\author{
Charles Jimenez Cruz ${ }^{1,2,3}$, Incheon Kang ${ }^{2,3}$, Woo Jung Lee ${ }^{2,3}$, and Chang Moo Kang ${ }^{2,3}$ \\ ${ }^{1}$ Department of Surgery, Makati City Hospital, Makati City, Philippines, \\ ${ }^{2}$ Division of HBP Surgery, Department of Surgery, Yonsei University College of Medicine, \\ ${ }^{3}$ Pancreatobiliary Cancer Center, Yonsei Cancer Center, Severance Hospital, Seoul, Korea
}

\begin{abstract}
Chronic pancreatitis is a benign inflammatory process that results symptoms pertaining to loss of endocrine and exocrine function. Pain poses a great challenge in the management of $\mathrm{CP}$ and intractable pain represents the main indication for surgical intervention. Surgical options for CP ranges from pancreatic resection to pure drainage procedures. Herein, we present the case of 68 year-old female with recurrent abdominal pain due to chronic pancreatitis, who underwent successful laparoscopic pancreatic neck transection and double pancreatico-jejunostomy (duct-to-mucosa). Pre-operative imaging revealed a uniformly dilated pancreatic duct with encrusted pancreatic stone in the pancreatic head near the ampulla of Vater, with no inflammatory mass. Pre-operative laboratory work-ups were all normal. Pancreas texture was noted to be intermediate to soft. During pancreatic neck transection, there was spontaneous deviation of distal stump laterally leaving an ample space to accommodate jejunal loop. PD measured $8 \mathrm{~mm}$. The standard duct to mucosa double layer simple interrupted suture was used for PJ anastomosis. There were no significant intra-operative events. No transfusion was required. Total operation time was 297 minutes, and it took 129 minutes for laparoscopic PJ completion. Immediate post-operative course was unremarkable. This case suggests laparoscopic double PJ can be an alternative surgical approach to reduce the pancreatic duct pressure in chronic pancreatitis. Based on accumulating experiences, long-term outcome also needs to be investigated to address potential role of this technique. (Ann Hepatobiliary Pancreat Surg 2019;23:291-294)
\end{abstract}

Key Words: Chronic pancreatitis; Pancreatico-jejunostomy

\section{INTRODUCTION}

Chronic pancreatitis (CP) is a benign inflammatory process that results in progressive replacement of pancreatic parenchyma by a fibrotic and inflammatory tissue. The end result may be an atrophied parenchyma or an inflammatory mass. ${ }^{1}$ The eventual pancreatic endocrine and exocrine dysfunction results to symptoms including chronic recurrent and severe pain, diabetes mellitus, steatorrhea and weight loss, all contributing to reduced quality of life. $^{2}$ Surgical options for CP ranges from pancreatic resection to pure drainage procedures. ${ }^{3}$ The choice of surgery depends on several factors such as size of pancreatic duct (PD), presence of inflammatory mass, suspicion of malignancy, irreversible duodenal stenosis. Herein, we present a case of chronic pancreatitis successfully managed by laparoscopic pancreatic neck transection and double pancreatico-jejunostomy $(\mathrm{PJ})$.

\section{CASE}

\section{Preoperative}

A 68-year-old female patient presented with recurrent and vague abdominal pain and discomfort for 5 years. She had been diagnosed with chronic pancreatitis with obstructing pancreatic head stone in another institution, for which an endoscopic attempt to remove the stone failed. Upon consult in our institution, preoperative imaging re-

Received: February 25, 2019; Revised: April 27, 2019; Accepted: April 30, 2019

Corresponding author: Chang Moo Kang

Division of HBP Surgery, Department of Surgery, Yonsei University College of Medicine, 50-1 Yonsei-ro, Seodaemun-gu, Seoul 03722, Korea Tel: +82-2-2228-2100, Fax: +82-2-313-8289, E-mail: cmkang@yuhs.ac

Copyright (C) 2019 by The Korean Association of Hepato-Biliary-Pancreatic Surgery

This is an Open Access article distributed under the terms of the Creative Commons Attribution Non-Commercial License (http://creativecommons.org/ censes/by-nc/4.0) which permits unrestricted non-commercial use, distribution, and reproduction in any medium, provided the original work is properly cited. Annals of Hepato-Biliary-Pancreatic Surgery • pISSN: 2508-5778 - elSSN: 2508-5859 


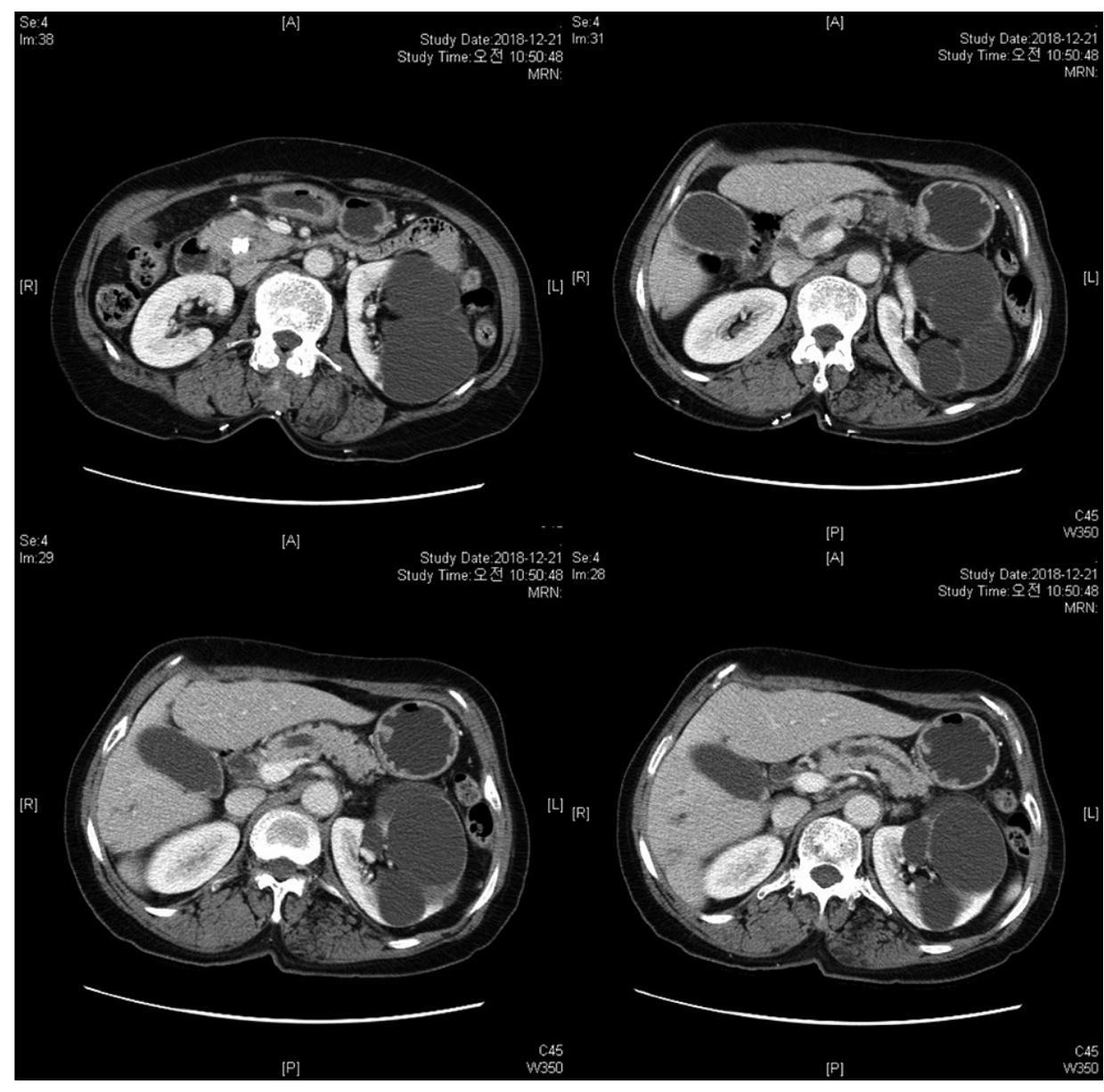

Fig. 1. Abdominal CT-scan: section at the pancreas level revealing the uniformly dilated pancreatic duct with encrusted stone at the pancreatic head near the ampulla of Vater. vealed uniformly dilated PD (Fig. 1) and obstructing encrusted pancreatic duct stone in near the ampulla of Vater, with no inflammatory mass. Preoperative blood work-ups were unremarkable including serum calcium, amylase, lipase, CEA, and CA19-9. Surgical intervention was contemplated and patient was initially scheduled for laparoscopic pancreatico-jejunostomy (side to side).

\section{Surgical approach}

For CP with ductal dilatation $>7 \mathrm{~mm}$ with no inflammatory mass, the recommended procedure is latero-lateral pancreatojejunostomy (Partington-Rochelle-procedure). ${ }^{1} \mathrm{~Pa}$ tient was placed in a supine position and general endotracheal anesthesia given. Operative field was cleansed and sterile drapes placed. Port placement was as in standard laparoscopic pancreatic resection (Fig. 2). Lesser sac was entered and the entire anterior surface of the pancreas exposed. Tunnel was created posterior to the pancreatic neck and was slung with nylon tape to prepare for transection. CP is typically associated with firm and fibrotic

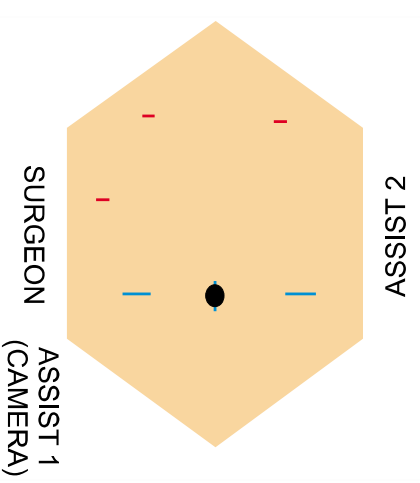

Fig. 2. Port placement and the position of the operating team (long: $12 \mathrm{~mm}$, short: $5 \mathrm{~mm}$ ).

gland. ${ }^{4,5}$ However, in this case, during dissection, pancreas texture was noted to be intermediate to soft. In this circumstance, longitudinal pancreatic duct opening might be associated with massive bleeding with potential pancreatic leak. Therefore, surgical plan was changed to transection of pancreatic neck portion with double end-to-side PJ (Fig. 3). On pancreatic neck transection, distal pancreatic 
stump (body and tail) was noted to be soft, and after little mobilization, actually deviated laterally causing ample space from the proximal stump (pancreatic head) that could accommodate a jejunal loop (Fig. 4A). Intra-operative decision was then made to do a roux-en-Y double end to side PJ (duct to mucosa). A $70 \mathrm{~cm}$ roux limb was constructed and the jejunum was transected $30 \mathrm{cms}$ from the duodeno-jejunal junction. Pancreatic duct measured approximately $8 \mathrm{~mm}$ (Fig. 4A). Anastomosis was via the standard duct to mucosa double layer simple interrupted suture (Fig. 4B, C). For the duct to mucosa anastomosis, a total of 8 stitches were placed in each PJ. Jejuno-jejunal anastomosis was done side-side using endo-GIA. Total operation time was 297 minutes, and it took 129 minutes for laparoscopic double PJ completion.

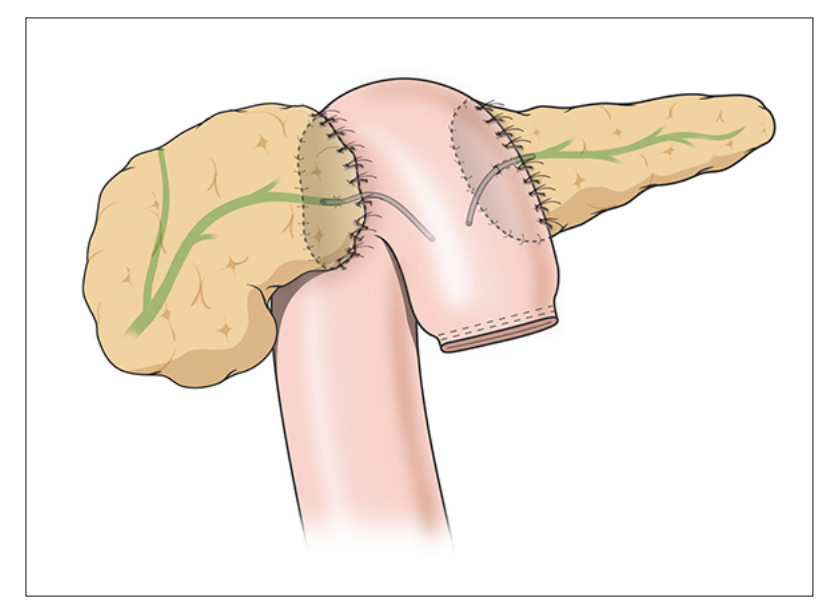

Fig. 3. Surgical concept of pancreatic transection with double layer duct to mucosa endo-to-side double P-J procedure.

\section{Postoperative course}

There were no significant intra-operative events. No blood transfusion was required. Immediate post-operative course was unremarkable. Preoperative NPIS (numerical pain intensity score) of patient was noted to be 1 , and then became 4 and 0 immediate postoperative and just prior to discharge, respectively. The patient was discharged on the $9^{\text {th }}$ post-operative day.

\section{DISCUSSION}

The pathophysiology of pain in CP is thought to begin with the increased pressure either in the ductal lumen or in the pancreatic parenchyma due to obstruction in PD. ${ }^{1,6}$ Chronic ductal and parenchymal hypertension results to ischemia and inflammation of pancreatic tissue that eventually lead to neural alteration and eventually pancreatic neuropathy, ${ }^{7}$ causing the characteristic pancreatic pain. Surgical management is offered to patients who failed to respond to medical and endoscopic intervention. Two approaches in surgical management of $\mathrm{CP}$ are pure drainage and resection with drainage. Pancreatic resection is reserved for patients with non-dilated PD, pancreatic head enlargement due to inflammatory mass, or if there is suspicion of malignancy. On the other hand, pure drainage procedure is recommended for patients with ductal dilatation $>7 \mathrm{~mm}$ without an inflammatory mass. ${ }^{1,8}$ Surgical drainage was shown to be superior over endoscopic drainage in management of pain in CP with ductal obstruction and dilatation. ${ }^{9,10}$ A widely accepted pure ductal drainage
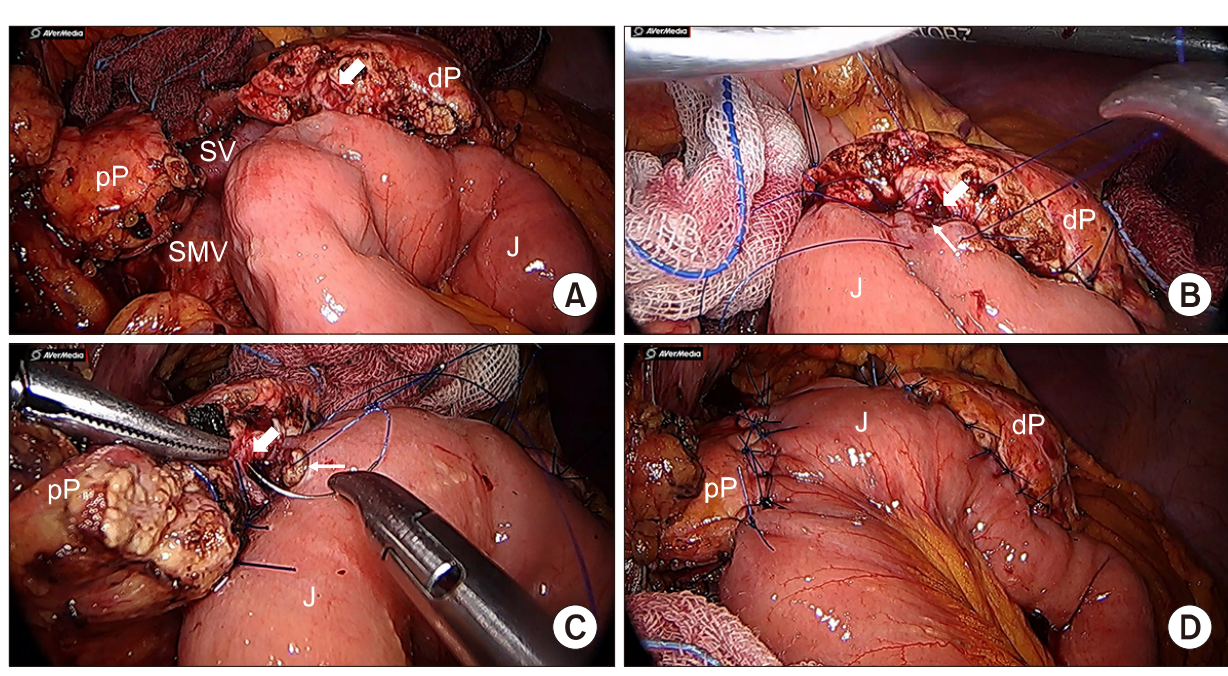

Fig. 4. Operation view after transection of the pancreatic neck. Note proximal pancreatic stump (pP) and the deviated distal stump (dP) with sufficient space to accommodate the jejunal loop (A), Distal stump P-J (B), Proximal stump P-J (C), and Completed double P-J (D). $\mathrm{SV}$, splenic vein; SMV, superior mesenteric vein; J, jejunum, thick white arrow (pancreatic duct), thin white arrow (jejunotomy). 
being performed is the latero-lateral pancreatico-jejunostomy which is the modification of Puestow-Gillesby procedure in 1960 by Partington and Rochelle. ${ }^{11}$ PartingtonRochelle technique is a pancreatic parenchyma-preserving procedure that attempts to reduce the loss of endocrine and exocrine function of the gland. ${ }^{3}$ Although it does not prevent the destruction of pancreatic tissue, ${ }^{12}$ surgical drainage done early in the course of the disease can delay or lessen the loss in pancreatic function. ${ }^{13,14}$ One technical disadvantage of latero-lateral PJ in laparoscopy is the need for a lengthy longitudinal opening of the PD from the tail to the right of mesenteric vessels, and hence, a long anastomosis suture line. The rationale being, all individual sacculations, caused by multiple point of obstruction, should be opened for adequate drainage. However in a uniformly dilated $\mathrm{PD}$, which is usually caused by single point of obstruction, an extensive opening of the PD is not required. ${ }^{15}$ Hence, in our case, a simpler pancreatic neck transection and $\mathrm{PJ}$ on the proximal and distal pancreatic stump would suffice in draining and decompressing the entire pancreas. In addition, it was thought that longitudinal opening of PD was not appropriate in this case, because the pancreatic parenchyma was not so hard that it would result in massive bleeding during that procedure.

As far as the author's knowledge, the present technique for laparoscopic pancreatic neck transection with double end-to-side PJ has never been reported for managing $\mathrm{CP}$. At this point, it is difficult to reach a conclusion, however, our experience suggests this technique is feasible and safe in managing well-selected CP. Potential indication is impacted single pancreatic duct stone in the pancreatic head with uniformly dilated distal PD. Further experiences are mandatory for investigating the effectiveness of the current surgical approach.

In conclusion, this is a presentation of a simpler alternative laparoscopic surgical approach for management of chronic pancreatitis patient with intermediate to soft pancreas and a uniformly dilated PD. Initial outcomes suggest that this can be an alternative approach, decompressing the pancreas with no need for parenchymal resection. Long-term outcome needs to be verified by accumulating experience and further study.

\section{ACKNOWLEDGEMENTS}

The authors thank MID (Medical Illustration \& Design), a part of the Medical Research Support Services of Yonsei University College of Medicine, for all artistic support related to this work.

\section{REFERENCES}

1. Strobel O, Büchler MW, Werner J. Surgical therapy of chronic pancreatitis: indications, techniques and results. Int J Surg 2009; 7:305-312.

2. Perwaiz A, Singh A, Chaudhary A. Surgery for chronic pancreatitis. Indian J Surg 2012;74:47-54.

3. Plagemann S, Welte M, Izbicki JR, Bachmann K. Surgical treatment for chronic pancreatitis: past, present, and future. Gastroenterol Res Pract 2017;2017:8418372.

4. Lin JW, Cameron JL, Yeo CJ, Riall TS, Lillemoe KD. Risk factors and outcomes in postpancreaticoduodenectomy pancreaticocutaneous fistula. J Gastrointest Surg 2004;8:951-959.

5. Wellner UF, Kayser G, Lapshyn H, Sick O, Makowiec F, Höppner $\mathrm{J}$, et al. A simple scoring system based on clinical factors related to pancreatic texture predicts postoperative pancreatic fistula preoperatively. HPB (Oxford) 2010;12:696-702.

6. Lew D, Afghani E, Pandol S. Chronic pancreatitis: current status and challenges for prevention and treatment. Dig Dis Sci 2017; 62:1702-1712.

7. D'Haese JG, Ceyhan GO, Demir IE, Tieftrunk E, Friess H. Treatment options in painful chronic pancreatitis: a systematic review. HPB (Oxford) 2014;16:512-521.

8. Jarnagin WR. Blumgart's surgery of the liver, biliary tract and pancreas. 6th ed. Philadelphia: Elsevier, 2017. 2120 p.

9. Ahmed Ali U, Pahlplatz JM, Nealon WH, van Goor H, Gooszen HG, Boermeester MA. Endoscopic or surgical intervention for painful obstructive chronic pancreatitis. Cochrane Database Syst Rev 2012;1:CD007884.

10. Cahen DL, Gouma DJ, Laramée P, Nio Y, Rauws EA, Boermeester $\mathrm{MA}$, et al. Long-term outcomes of endoscopic vs surgical drainage of the pancreatic duct in patients with chronic pancreatitis. Gastroenterology 2011;141:1690-1695.

11. Fragulidis GP, Vezakis A, Dellaportas D, Sotirova I, Koutoulidis $\mathrm{V}$, Kontis E, et al. "Puestow modified procedure in the era of advanced endoscopic interventions for the management of chronic lithiasic pancreatitis. A two cases report". Int J Surg Case Rep 2015;15:85-88.

12. Warshaw AL, Popp JW Jr, Schapiro RH. Long-term patency, pancreatic function, and pain relief after lateral pancreaticojejunostomy for chronic pancreatitis. Gastroenterology 1980;79:289-293.

13. Nealon WH, Thompson JC. Progressive loss of pancreatic function in chronic pancreatitis is delayed by main pancreatic duct decompression. A longitudinal prospective analysis of the modified puestow procedure. Ann Surg 1993;217:458-466; discussion 466-468.

14. Ahmed Ali U, Nieuwenhuijs VB, van Eijck CH, Gooszen HG, van Dam RM, Busch OR, et al.; Dutch Pancreatitis Study Group. Clinical outcome in relation to timing of surgery in chronic pancreatitis: a nomogram to predict pain relief. Arch Surg 2012;147:925-932.

15. Partington PF, Rochelle RE. Modified Puestow procedure for retrograde drainage of the pancreatic duct. Ann Surg 1960;152: 1037-1043. 